\title{
XPS study of the chemical structure of the nickel/silicon interface
}

\author{
P. J. Grunthaner and F. J. Grunthaner \\ Jet Propulsion Laboratory, California Institute of Technology, Pasadena, California 91103
}

\author{
J.W. Mayer ${ }^{a)}$ \\ California Institute of Technology, Pasadena, California 91125
}

(Received 20 February 1980; accepted 15 May 1980)

\begin{abstract}
The chemical nature of the $\mathrm{Ni} / \mathrm{Si}, \mathrm{Ni} / \mathrm{Ni}_{2} \mathrm{Si}$ and $\mathrm{Si} / \mathrm{Ni}_{2} \mathrm{Si}$ interfaces have been investigated using $\mathrm{x}$-ray photoelectron spectroscopy. Peak position, line shapes, and envelope intensities are used to probe the compositional structure of these systems. Two approaches have been employed: one approach examines the advancing planar silicicie front by dynamically monitoring the in situ formation of $\mathrm{Ni}_{2} \mathrm{Si}$. This has the advantage of allowing examination of a realistic interface which is bounded on either side by an extended solid. The second approach follows the development of the $\mathrm{Si} / \mathrm{Ni}$ interface using $\mathrm{UHV}$ depositions of thin layers of $\mathrm{Ni}$ on $\mathrm{Si}<100>\cdot{ }^{4} \mathrm{He}^{+}$backscattering is used to follow the progression of the thin film reaction and to provide quantitative information on atomic composition. These experiments demonstrate that the $\mathrm{Ni} / \mathrm{Ni}_{2} \mathrm{Si}$ interface consists of a $\mathrm{Ni}$-rich silicide transitional phase while the $\mathrm{Si} / \mathrm{Ni}{ }_{2} \mathrm{Si}$ interface shows a transitional structure which is correspondingly Si-rich. Intensity analysis indicates that these interfacial regions are at least $22 \AA$ wide for $\alpha$-Si substrates and $9-14 \AA$ wide for crystalline $\mathrm{Si}$. The as-deposited $\mathrm{Ni} / \mathrm{Si}$ interface cannot be described as a unique singlephase, but rather as a chemically graded transitional region showing a composition which varies from Si-rich to Ni-rich silicides.
\end{abstract}

PACS numbers: $73.40 . \mathrm{Ns}, 79.60 . \mathrm{Gs}, 82.80 . \mathrm{Di}$

\section{INTRODUCTION}

The solid-phase reactions of metal films with silicon have attracted much attention in recent years because of the increasing applications of silicides in device technology. Studies of transition metal silicides have concentrated on the formation kinetics, stoichiometry, and stability of the solid-state reaction products as well as the mass transport across the reaction interface. ${ }^{1}$ Only a few studies have dealt with the nature of the chemical bonding within the silicides and at their interfaces. ${ }^{2-4}$ In this paper, we report the results of our investigation of the $\mathrm{Ni} / \mathrm{Si}, \mathrm{Ni} / \mathrm{Ni}_{2} \mathrm{Si}$, and $\mathrm{Si} / \mathrm{Ni}_{2} \mathrm{Si}$ interfaces using $\mathrm{x}$-ray photoelectron spectroscopy (XPS).

Two approaches have been employed to investigate these interfaces. The first approach, which has been used to examine the $\mathrm{Ni}$ /silicide and $\mathrm{Si} /$ silicide interfaces, involves dynamically monitoring the advancing reaction front during in situ growth. In the second approach, as-deposited $\mathrm{Ni} / \mathrm{Si}$ interfacial properties have been studied by sequentially evaporating monolayer Ni films on Si. Rutherford backscattering has been combined with XPS to quantify the photoemission experiment.

\section{EXPERIMENTAL}

Crystalline $\mathrm{Si}(100)$ and thermally oxidized Si wafers were used as substrates for the deposition of thin $\mathrm{Si}$ and $\mathrm{Ni}$ films. Prior to deposition, these substrates were cleaned using standard procedures. A background pressure of $5 \times 10^{-7}$ Torr $\left(6.65 \times 10^{-5} \mathrm{~Pa}\right)$ was maintained during the evaporation. The $\mathrm{Si}$ and $\mathrm{Ni}$ films were evaporated using an e-beam source at a rate of 40 and $20-35 \AA / s$, respectively.

Prior to examination by XPS, the nickel oxide that had formed on the surfaces of the $\mathrm{Ni} / \mathrm{Si}$ and $\mathrm{Ni} /\langle 100\rangle \mathrm{Si}$ samples was etched off under a $\mathrm{N}_{2}$ atmospherc by spinning the sample at $3600 \mathrm{rpm}$ and adding dropwise $500 \mu l$ of $1: 1 \mathrm{HCl}$ in ethanol, followed by $500 \mu$ lof ethanol. The $\mathrm{SiO}_{2}$ layer that had formed on the $\mathrm{Si} / \mathrm{Ni}$ sample was removed with several drops of a 1:10 $\mathrm{HF}$ in ethanol solution using the same spinning technique. The sample inlet port of the spectrometer is connected to the $\mathrm{N}_{2}$ drybox so that no additional oxygen contamination occurred after etching.

The UHV Ni evaporations were performed in situ in the XPS spectrometer at a pressure of $2-5 \times 10^{-9}$ Torr (2.6-6.6 $\left.\times 10^{-7} \mathrm{~Pa}\right)$. The base pressure was $5 \times 10^{-10} \mathrm{Torr}\left(6.6 \times 10^{-8}\right.$ $\mathrm{Pa}\rangle$. Prior to loading, the $\langle 100\rangle$ Si substrate was cleaned by etching with $200 \mu \mathrm{l}$ of $1: 10 \mathrm{HF}$ in ethanol under a $\mathrm{N}_{2}$ atmosphere as described above. This was followed by a $500 \mu \mathrm{l}$ ethanol rinse. No oxygen and negligible carbon could be detected on the substrate prior to Ni evaporation.

Where in situ reactions were performed, the samples were heated to $548 \mathrm{~K}$. The pressure during the heating was better than $2 \times 10^{-9}$ Torr $\left(2.6 \times 10^{-7} \mathrm{~Pa}\right)$. The samples were cooled to $298 \mathrm{~K}$ for data accumulation.

The XPS experiments were performed using a modified HP5950A spectrometer which has been described elsewhere. ${ }^{5}$ After XPS analysis, the silicide composition was determined using $2.0 \mathrm{MeV}{ }^{4} \mathrm{He}^{+}$backscattering. ${ }^{6}$ 


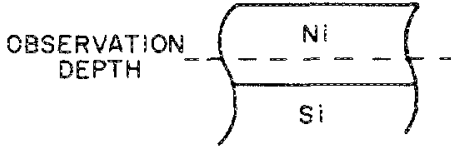

(a)

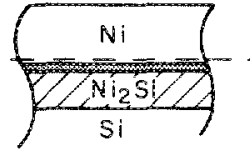

(b)

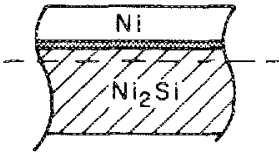

(c)

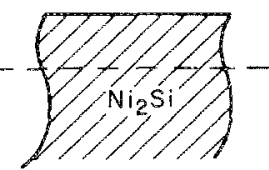

(d)
FG. 1. Schematic representation of the progression of the $\mathrm{Ni} / \mathrm{Ni} S \mathrm{Si}$ interface.

\section{RESULTS AND DISCUSSION}

\section{A. Dynamic monitoring of the silicide growth front}

This dynamic approach exploits the exponential attenuation of photoemission intensities to examine the advancing silicide growth front. To illustrate the procedure, consider the reaction of a nickel film on a silicon substrate. Rutherford backscattering studies ${ }^{7}$ have shown that the formation of the silicide proceeds as a planar front as shown in Fig. 1. Upon heating, an initial phase $\mathrm{Ni}_{2} \mathrm{Si}$ forms at the Ni/Si interface. With continued heating, the width of the silicide layer increases until the Ni film has been consumed as shown in Figs. 1(b), (c), and (d). The planar progression of the $\mathrm{Ni}_{2} \mathrm{Si}$ phase allows one to examine the $\mathrm{Ni} / \mathrm{Ni}_{2} \mathrm{Si}$ interface by utilizing the finite information depth of XPS. The exponential attenuation of photoemission intensities establishes an effective observation depth as shown in Fig. I. If the initial Ni film is sufficiently thick [Fig. 1(a)], only signal from Ni metal will be detected. By monitoring the Si signal as the sample is heated in situ, one can examine the emerging $\mathrm{Ni} / \mathrm{Ni} 2 \mathrm{Si}$ interface and bulk $\mathrm{Ni}_{2} \mathrm{Si}$ as they advance into the observation depth [Figs. 1(b-d)]. There are two major advantages to studying the interface with this dynamic approach. First, it allows examination of a more "realistic" interface in that the interface is bounded on both sides by an extended solid. Most interfacial studies employ multiple monolayer depositions of a metal on silicon to approximate the interface. The presence of an extended solid on each side of the interfacial region will impose different bonding restrictions on these atoms as compared to the presence of a vacuum. In particular, the stoichiometry and local bonding geometries of the compounds found within this transition region should be strongly affected by the nature of the overlayer and the strain induced by its presence. Secondly, this dynamic approach allows examination of the interface without the chemical and structural perturbations caused by conventional ion and chemical profilings. ${ }^{8}$

\section{The Si/ $\mathrm{Ni}_{2} \mathrm{Si}$ interface}

The $\mathrm{Si} / \mathrm{Ni}_{2} \mathrm{Si}$ interface may be examined as discussed above by monitoring a sample of Si deposited on $\mathrm{Ni}$ as a function of time during in situ silicide formation. The emerging photoemission signal from the $\mathrm{Ni}$ core levels allows one to interrogate the advancing $\mathrm{Si} / \mathrm{Ni}_{2} \mathrm{Si}$ reaction front. Figure 2 plots the progression of the Ni $2 p_{3 / 2}$ photoelectron signal obtained for the $\mathrm{Si} / \mathrm{Ni}$ sample at various intervals during the silicide formation. In Fig. 2(a), the reaction front has not advanced far enough to be within the sampling depth of the spectroscopy and, correspondingly, no N: $2 p$ signal is observed. The first Ni $2 p$ signal [Fig. $2($ b $)]$ appears at a binding energy of $853.7 \mathrm{eV}$. As the sample heating continues, the Ni $2 p$ signal increases in intensity [Fig. 2(c)]. After approximately a 25-fold increase in intensity, a shoulder appears on the low binding energy side at $85.3 .0 \mathrm{eV}[\mathrm{Fig} .2(\mathrm{~d})]$ and grows in intensity until it dominates the spectrum completely [Fig. 2(e)]. This end phase was determined to be $\mathrm{Ni}_{2} \mathrm{Si}$ using ${ }^{4} \mathrm{He}^{+}$backscattering. The thickness of the silicon overlayer when the Ni signal is first detected may be estimated using the known exponential dependence of photoemission intensity on overlayer thickness." Using these relationships, we have fornd that at the point where the interfacial signal of Fig. $2(\mathrm{~b})$ is observed, the thickness of the Si overlayer is $2.6 \lambda$, where $\lambda$ is the electron escape depth. Assuming an escape depth of $25 \AA$, as has been determined for $\mathrm{Si} 2 p$ electrons from crystalline $\mathrm{Si},{ }^{10}$ the calculated Si overlayer thickness is $\sim 65 \AA$. This serves as a reasonable estimate because the escape depth in amorphous $\mathrm{Si}$ should be greater than that found for crystalline Si; however, the escape depth of Ni $2 p$ electrons should be smaller than that found for Si $2 p$ electrons due to the kinetic energy dependence of the electron escape depth.

The observed Ni $2 p$ binding energies decrease in the order $\mathrm{NiSi}>\mathrm{Ni}_{2} \mathrm{Si}>\mathrm{Ni}^{0}$. These core level spectra, as well as the corresponding valence band spectra ${ }^{11}$ indicate that charge is transferred from $\mathrm{Ni}$ to Si upon $\mathrm{Ni}-\mathrm{Si}$ bond formation. The increasing $\mathrm{Ni} 2 p$ binding energy is therefore a measure of the number and strength of heteropolar bonds formed in a par-

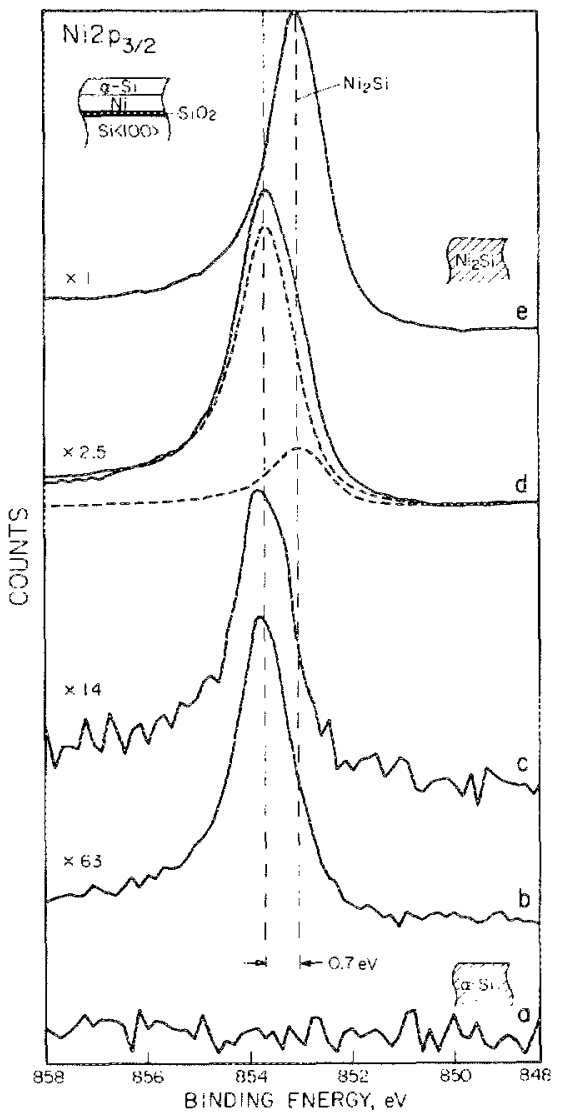

FrG. 2. The Ni $2 p_{3 / 2}$ spectra obtained as a function of time as the $\mathrm{Si} / \mathrm{Ni}_{2} \mathrm{Si}$ interface advanced toward the sample. surface. The dashed spectra in (d) represent components determined using least siulare criterion. The lineshape determined for $\mathrm{Nig} \mathrm{Si}$ in (e) was used for these component peaks. 


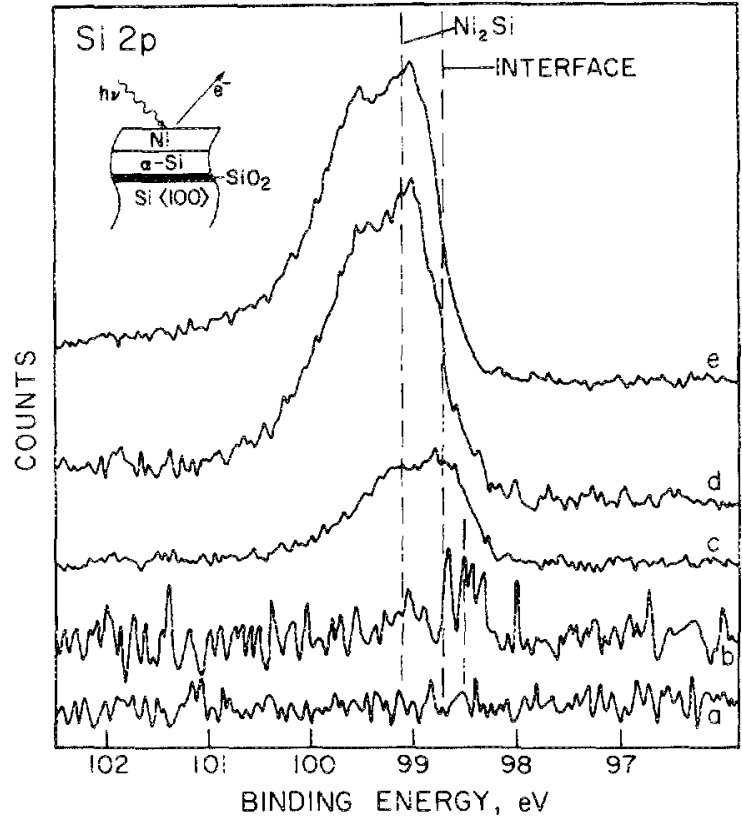

FIG. 3. The Si $2 p$ spectra obtained as a function of time as the $\mathrm{Ni} / \mathrm{Ni}_{2} \mathrm{Si}$ irkterface approached the sample surface. Amorphous $\mathrm{Si}$ was used as the substrate.

ticular structure. The first $\mathrm{Ni} 2 p$ signal in $\mathrm{Fig}$. 2(b) appears at a binding energy $0.7 \mathrm{eV}$ higher than the corresponding energy found for the bulk Nigi [Fig. 2(e)]. This indicates that the local atomic structure of the $\mathrm{Ni}$ in the interfacial region is in a Si-rich environment as compared to that found in bulk $\mathrm{Ni}_{2} \mathrm{Si}$. This suggests that the transitional region between $\mathrm{Si}$ and $\mathrm{Ni}_{2} \mathrm{Si}$ consists of a silicon rich silicide. Estimates of the width of this transitional region will be discussed in Sec. III A.3.

\section{The $\mathrm{Ni} / \mathrm{Ni}_{2}$ Si interface}

The $\mathrm{Ni} / \mathrm{Ni}_{2} \mathrm{Si}$ interface may be studied by monitoring a sample of $\mathrm{Ni}$ deposited on Si during in situ silicide growth. In this case, the emergent $\mathrm{Si} 2 p$ photoelectron intensity is examined as the $\mathrm{Ni} / \mathrm{Ni}_{2} \mathrm{Si}$ reaction front advances into the observation depth of the spectroscopy. Figure 3 plots the progression of the Si $2 p$ signals obtained for the $\mathrm{Ni} / \mathrm{Si}$ sample as a function of time during silicide formation. In Fig. 3(a), the silicide reaction front has not yel advanced within the observation depth and thus no Si $2 p$ intensity is detected. With continued heating, the $\mathrm{Ni} / \mathrm{Ni}_{2} \mathrm{Si}$ reaction front advances until the first weak Si $2 p$ signal is observed at $98.5 \mathrm{eV}[\mathrm{Fig} .3(\mathrm{~b})]$ and at $98.7 \mathrm{eV}$ a short time later [Fig. 3(c)]. The Si $2 p$ position in Fig. $3(\mathrm{~b})$ is only an estimation since the low signal to noise ratio makes an accurate determination of its binding energy difficult. In the final spectrum, Fig. 3(e), the thin film has reacted completely to form $\mathrm{Ni}_{2} \mathrm{Si}$ as determined by ${ }^{4} \mathrm{He}^{+}$backscattering. The Si $2 p$ signal from this end phase falls at a binding energy of $99.1 \mathrm{eV}$. The thickness of the $\mathrm{Ni}$ overlayer when the first $\mathrm{Si} 2 p$ signal is detected has been determined to be $\sim 22$ $\not$ using the exponential dependence of the Si $2 p$ signal on the overlayer thicknoss.

The observed Si $2 p$ binding energies decrease in the order $\mathrm{Si}^{\circ}>\mathrm{Ni}_{2} \mathrm{Si}>\mathrm{NiSi}$. This again reflects the formation of an increasing number of heteropolar $\mathrm{Ni}-\mathrm{Si}$ bonds. The first $\mathrm{Si} 2 \mathrm{p}$ signal [Figs. 3(b) and (c)] falls at a binding energy $0.4-0.6 \mathrm{eV}$ lower than the Si $2 p$ binding energy found for bulk $\mathrm{Ni}_{2} \mathrm{Si}$ [ Fig. $3(\mathrm{e})]$. This shift of the Si $2 p$ position toward higher binding energy as the bulk $\mathrm{Ni}_{2} \mathrm{Si}$ is formed indicates the interfacial $\mathrm{Si}$ atoms are experiencing a greater degree of $\mathrm{Ni}$ coordination than that encountered in bulk $\mathrm{Ni}_{2} \mathrm{Si}$. This suggests that the transition between $\mathrm{Ni}$ and $\mathrm{Ni}_{2}$ Si consists of a nickel rich silicide.

The $\mathrm{Ni} / \mathrm{Ni}_{2} \mathrm{Si}$ interface was also examined using a $\langle 100\rangle$ Si substrate instead of the amorphous Si material discussed above. Again, the emergent Si $2 p$ signal was monitored with time as the $\mathrm{Ni} / \mathrm{Ni}_{2}$ Si reaction front advanced during the in situ heat treatment. The progression of the Si $2 p$ position and intensity is plotted in Fig. 4. In Fig. 4(a), no Si $2 p$ intensity is detected since the reaction front has not progressed into the observation depth. As the $\mathrm{Ni} / \mathrm{Ni}_{2} \mathrm{Si}$ front proceeds toward the surface, the spectra shown in Figs. $4(b)$ through $4(d)$ are obtained. In the final spectrum, Fig. $4(e)$, the reaction has completely consumed the Ni film yielding an end product of $\mathrm{Ni}_{2} \mathrm{Si}$. Notice in Fig. $4(\mathrm{e})$ that the $0.6 \mathrm{eV}$ spin-orbit splitting of the Si $2 p$ line is clearly resolvable. A spectrum of clean Si has been plotted over the spectrum of the bulk $\mathrm{Ni}_{2} \mathrm{Si}$ to delineate the silicide signal from the broad low intensity signal appearing on the high binding energy side. Previous studies have shown this intensity to be due to silicon suboxides that are formed as the silicide reaction front sweeps out the inpurity oxygen present in the evaporated Ni films. ${ }^{13}$ In Figs. $4(b)$ through (d), the characteristic Si $2 p$ spin-orbit splitting

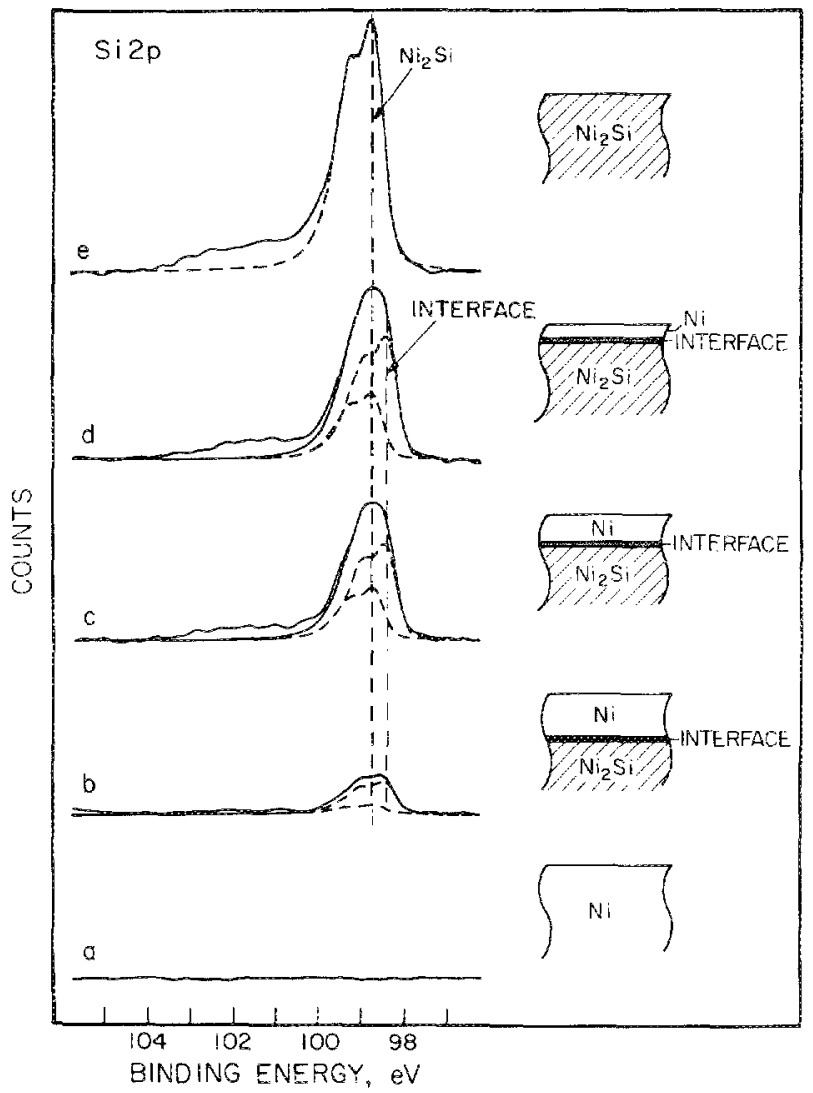

FIG. 4. The Si 2 p spectra obtained as the $\mathrm{Ni} / \mathrm{Ni}$ Si interface advanced toward the surface. A (100) Si substrate was used. The dashed spectra in (b) through (d) represent peak components determined using the least square criterion discussed in the text. The dashed spectrum in (e) is of a clean Si substrate (shifted in energy for comparison). 


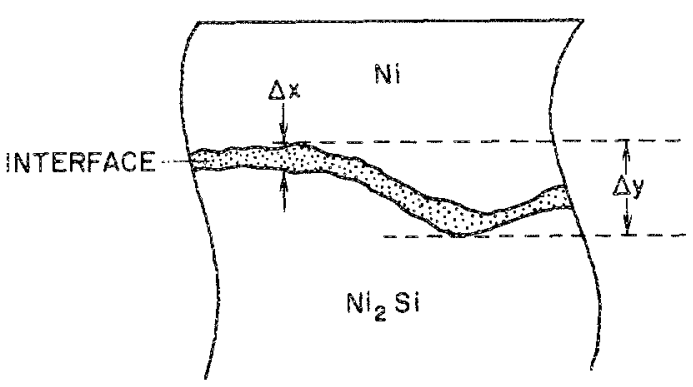

FIG. 5. Schematic of the $\mathrm{Ni} / \mathrm{Ni}_{2} \mathrm{Si}$ interface.

is no longer resolvable. This suggests that the peak envelope consists of at least two closely spaced signals. To test this hypothesis, two signals corresponding to a bulk and an interfacial signal were fitted to the data using a least squares minimization criterion. The clean $\mathrm{Si} 2 \mathrm{p}$ signal shown in Fig. $4(\mathrm{e})$ was used as the lineshape model for the bulk and interfacial signals. The position found for bulk Nigsi in Fig. 4(e) was held constant while the height of this signal and the position and height of the interface signal was allowed to vary in each of the spectra in Figs. 4 (b) through (d). This yrocedure corresponds to a three parameter analysis of the observed line shapes. In this figure, the fitted spectra and their sum are plotted over the raw data. Three features of the fitted spectra suggest that they are a reasonable estimation of the composite peaks within the raw data envelope. First, the position of the interface signal was found to remain constant for spectra 4(b) through (d). Secondly, the ratio of the intensity of the interface signal to the intensity of the bulk $\mathrm{Ni}_{2} \mathrm{Si}$ signal was found to bo the same in Fig. $4(c)$ as in (d). As will be discussed in Sec. III A.3, theory predicts that this ratio should be constant. In Fig. 4(b), the ratio is somewhat brger than that found for Figs. $4(\mathrm{c})$ and (d), but this may be atiributed to the interfacial region not yet being entirely within the observation depth of the spectroscopy at this early stage. Thirdly, the $0.4 \mathrm{eV}$ shift of the $\mathrm{Si} 2 \mathrm{p}$ interface signal relative to the bulk $\mathrm{Ni}_{2} \mathrm{Si}$ signal is completely consistent with the shift $(0.40 .6 \mathrm{eV})$ found for the interface signal using an amorphous substrate (Fig. 3).

Again, the observation that the Si $2 p$ interface signal occurs at a lower binding energy than the bulk $\mathrm{Ni}_{2}$ Si signal indicates the transition region between $\mathrm{Ni}$ and $\mathrm{Ni}_{2}$ Si consists of a $\mathrm{Ni}$-rich silicide. The essential difference between the $\mathrm{Ni} / \mathrm{Ni}_{2} \mathrm{Si}$ interfaces grown on crystalline and amorphous Si substrates is the width of the transitional phase. This is discussed in more detail in the following section.

\section{Interfacial widths}

The widths of the $\mathrm{Ni} / \mathrm{Ni}_{2} \mathrm{Si}$ and $\mathrm{Si} / \mathrm{Ni}_{2} \mathrm{Si}$ transitional regions can be estimated from the relative intensities of the bulk $\mathrm{Ni}_{2} \mathrm{Si}$ and interface photoclectron intensities using the known exponential dependence of a substrate intensity on overlayer thickness. ${ }^{9}$ It can be shown that the ratio of the Si $2 p$ intensity from the interfacial region, $I_{S i}$, to the $S i 2 p$ intensity from the bulk $\mathrm{Ni}_{2} \mathrm{Si}, I_{S i}^{\text {bulk }}$, is determined by the interfacial width $\Delta x$ and is independent of the thickness of the Ni overlayer. That is,

$$
\frac{I_{\mathrm{Si}}^{\mathrm{int}}}{I_{\mathrm{Si}}^{\mathrm{bulk}}}=\frac{D_{\mathrm{Si}}^{\mathrm{int}} \lambda_{\mathrm{Si}}^{\mathrm{int}}}{D_{\mathrm{Si}}^{\mathrm{bulk}} \lambda_{\mathrm{Si}}^{\mathrm{bulk}}}\left(e^{\Delta x /\left(\lambda_{\mathrm{Si}}^{\mathrm{ln}} \sin \theta\right)}+1\right),
$$

where $D_{\mathrm{Si}}^{\mathrm{int}}$ and $D_{\mathrm{Si}}^{\text {bulk }}$ are the atomic densities of $\mathrm{Si}$ in the interfacial region and in the bulk NigSi, respectively; $\lambda_{\mathrm{Si}}$ and $\lambda_{\mathrm{Si}}^{\text {bulk }}$ are the electron escape depths of the Si $2 p$ electrons in the interfacial region and bulk $\mathrm{NigSi}$, respectively; and $\theta$ is the angle between the detector and the plane of the sample $\left(38.5^{\circ}\right)$.

The value of $\Delta x$ is a measure of the average interface width. Large scale undulations of the interface, $\Delta y$, as shown in Fig, 5 , do not affect the estimations for $\Delta x$ since $I_{S i}^{i n t} / I_{S i}^{\text {bulk }}$ is independent of the thickness of the $\mathrm{Ni}$ overlayer. An analogous equation can be writien for the case of a Si overlayer using the $\mathrm{Ni} 2 p$ interface and buk $\mathrm{Ni}_{2} \mathrm{Si}$ signal intensities.

There are two limiting cases to be considered. If the interfacial region is sufficiently wide, then Iint/rbulk will be much greater than unity and initially, only the interface signals should be seen as the silicide reaction front advances. As the interface reaches the sample surface and then dissipates, the bulk $\mathrm{Ni}_{2} \mathrm{Si}$ signal should begin to dominate the spectra. This wide interfacial region characterizes the situation in Figs. 2 and 3 where deposited Si and Ni films were used. Equation (1) may be rewritten as

$$
\Delta x=\lambda_{S i}^{\mathrm{int}} \sin \theta \ln \left[\frac{I_{\mathrm{Si}}^{\mathrm{int}} / I_{S \mathrm{i}}^{\mathrm{bulk}}}{R}+1\right]
$$

where

$$
R=\frac{D_{S i}^{\text {int }} \lambda_{S i}^{\text {ink }}}{D_{S i}^{\text {bulk }} \lambda_{S i}^{\text {bulk }}}
$$

$D_{S i}^{\text {int }}<D_{S i}^{\text {bulk }}$ and $\lambda_{S i}^{\text {int }} \sim \lambda_{S i}^{\text {bilk }}$ since the interface consists of a Ni-rich silicide. We estimate that the interface signal will appear to dominate when the bulk Ning $\mathrm{Si}$ intensity is only 0.1 of the interface intensity. This corresponds to $\Delta x>1.5 \mathrm{~A}_{\mathrm{Si}}^{\mathrm{in}}$. This places a lower limit on the $\mathrm{Ni} / \mathrm{Ni}{ }_{2} \mathrm{Si}$ interface width of $22 \AA$ if a "metalliclike" escape depth of $15 \AA$ is assumed.14

Analogously, a lower limit of $1.5 \lambda_{N i}^{\mathrm{int}}$ may be placed on the $\mathrm{Si} / \mathrm{Nig} \mathrm{Si}$ interface width. This again corresponds to a transitional width of at least $22 \AA$ if $\lambda$ is $15 \AA$.

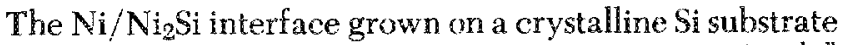
is the second limiting case to be considered. Here, the $I_{\mathrm{Si}}^{\mathrm{int}} / I_{\mathrm{Si}}^{\text {bulk }}$ ratio is such that the $5 \mathrm{i} 2 \mathrm{p}$ siguals corresponding to both the interfacial and bulk $\mathrm{Ni}_{2} \mathrm{Si}$ are detected simultaneously. From Figs. 4(c) and (d), the ratio of interface to bulk signal is found to be 1.67 . Since the $\mathrm{Ni} / \mathrm{Ni}_{2} \mathrm{Si}$ interface consists of a $\mathrm{Ni}$-rich silicide, again $D_{\mathrm{Si}}^{\text {int }}<D_{\mathrm{Si}}^{\text {bulk }}$ and $\lambda_{\mathrm{Si}}^{\text {int }} \sim \lambda_{\mathrm{Si}}^{\text {bulk }}$. This corresponds to $\Delta x>0.6 \lambda_{\mathrm{si}}^{\mathrm{int}}$. Assuming a $15 \AA$ escape depth, this corresponds to a lower limit of $9 \AA$ for the interface width. If the density of $\mathrm{Si}$ atoms at the interface was only one-half that found in bulk $\mathrm{Ni}_{2} \mathrm{Si}$, this would give an upper bound for the estimation of $\Delta x$ of $14 \AA$. Although the absolute values of these interfacial widths depend on the accuracy of the assumed escape depth, a relative comparison of the widths should be quite reliable. The essential difference between the $\mathrm{Ni} / \mathrm{Ni} 2 \mathrm{Si}$ interface using a crystalline substrate as compared to an amorphous substrate is that the former is $2-3$ times narrower $\left(0.6 \lambda_{\mathrm{Si}}^{\text {int }}\right)$ than the latter $\left(1.5 \lambda_{\mathrm{Si}}^{\mathrm{int}}\right)$.

\section{UHV depositions of thin Kiflins on (100) Si}

The as-deposited $\mathrm{Ni} / \mathrm{Si}$ interface was investigated by monitoring the Ni $2 p$ and Si $2 p$ photoelectron signals as thin 


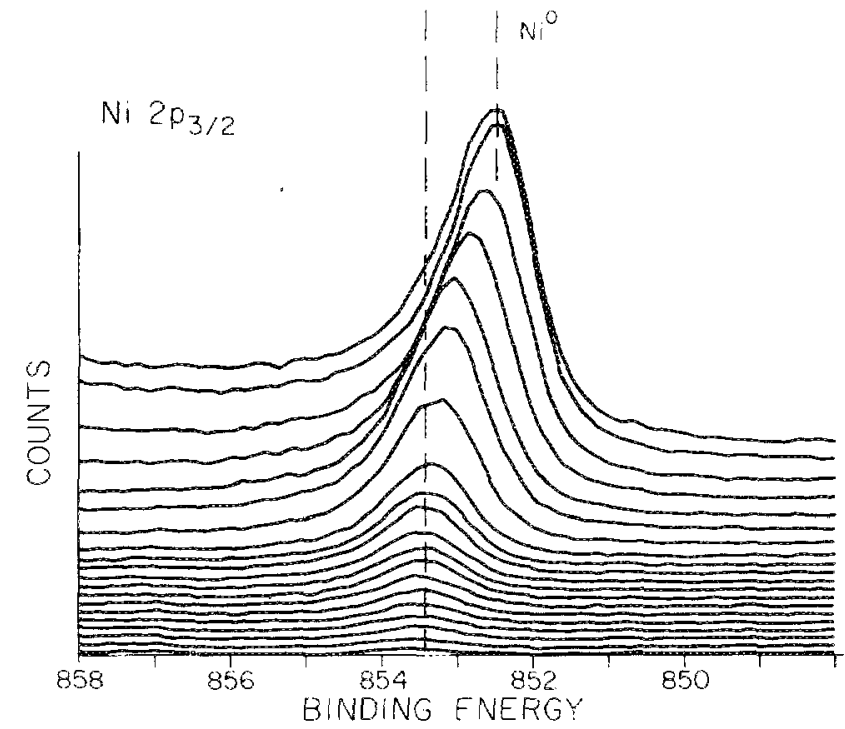

FIG. 6. Ni $2 p_{3 / 2}$ spectra obtained after sequential depositions of thin Ni films on $\langle 100\rangle$ Si.

Ni films were evaporated in situ onto a clean $\langle 100\rangle$ substrate. Figure 6 plots the $\mathrm{Ni} 2 p$ spectra obtained after sequential evaporations of $\mathrm{Ni}$ metal. The Ni films ranged from $\sim 8.0 \times$ $10^{13} \mathrm{Ni} / \mathrm{cm}^{2}(\sim 0.1$ monolayer $)$ to $\sim 1.9 \times 10^{16} \mathrm{Ni} / \mathrm{cm}^{2}(\sim 30$ monolayers), as determined with ${ }^{4} \mathrm{He}^{+}$backscattering using an independently calibrated standard. ${ }^{12}$ The first detectable $\mathrm{Ni} 2 p$ signal appears at a binding energy of $853.6 \mathrm{eV}$ and eventually shifts smoothly to the position for Ni metal at 852.5 $\mathrm{eV}$. This indicates that the initial monolayers of Ni atoms experience a strong chemical interaction with the Si substrate even at room temperature. Approximately 5-10 monolayers are present before the $\mathrm{Ni} 2 p$ begins to shift toward a pure $\mathrm{Ni}$ metai signal.

After $\sim 30$ monolayers of $\mathrm{Ni}$ had been evaporated and a pure Ni metal signal established, the sample was heated in situ to yield $\mathrm{Ni}_{2} \mathrm{Si}$. Figure 7 plots the $\mathrm{Ni} 2 p$ and corresponding $\mathrm{Si}$ $2 p$ signals for a $\langle 100\rangle$ Si substrate with $\sim 0.1$ monolayers $\mathrm{Ni}$ [Fig. 7(a)], 30 monolayers $\mathrm{Ni}[$ Fig. $7(\mathrm{~b})]$, and the Nig Si film after heat treatment [Fig. 7(c)]. The Ni $2 p$ signal in Fig. 7(a) corresponding to the submonolayer coverage of $\mathrm{Ni}$ is $0.4 \mathrm{eV}$ higher in binding energy than the bulk $\mathrm{Ni}_{2} \mathrm{Si}$ signal in Fig. 7(c). As discussed previously, this suggests that the metal atoms have reacted to yield a $\mathrm{Si}$-rich silicide relative to $\mathrm{Ni}_{2} \mathrm{Si}$. 'Tho corresponding Si $2 p$ signal in Fig. 7 (a) is that of the pure Si substrate since the reacted Si signal is too weak to be detected in the presence of the strong substrate signal. In Fig. 7(b), the overlayer is sufficiently thick that only the $\mathrm{Ni} 2 p$ corresponding to $\mathrm{Ni}$ metal is detected. In the respective $\mathrm{Si} 2 p \mathrm{re}$ gion, the exponential attenuation of photommission intensities may again be exploited to investigate the chemical nature of the remainder of the interfacial region. The last Si $2 p$ signal detectable must necessarily correspond to the "topmost" silicon atoms of the interface. Relative to the Si $2 p$ signal from the bulk $\mathrm{Ni}_{2} \mathrm{Si}$ shown in Fig. 7(c), the Si $2 p$ interface signal in Fig. 7(b) is shifted $0.5 \mathrm{eV}$ toward lower binding energy. This indicates that the Si atoms in this region are in a more $\mathrm{Ni}$-rich silicide environment than that found in $\mathrm{Ni}_{2}$ Si. The binding energy of the $\mathrm{Si} 2 p$ core level from $\mathrm{Ni}_{2} \mathrm{Si}$ is observed at an energy similar to that obtained from the core level of the $\mathrm{Si}$ substrate. This is attributable to the difference in final state relaxation anticipated for semimetal and semiconductor materials. We circumvent this ambiguity by referencing the interface signal to the final $\mathrm{Ni}_{2} \mathrm{Si}$ phase rather than to the initial Si substrate. The first detectable Ni $2 p$ signal and the last detectable Si $2 p$ signal thus suggesi that the Ni/Si transition region cannot be described as a single unique phase. Instead, these signals indicate the presence of a chemically graded transition region which ranges in stoichiometry from a Si-rich silicide on the $\langle 100\rangle$ Si side of the interface to a Nirich silicide on the $\mathrm{Ni}$ metal side.

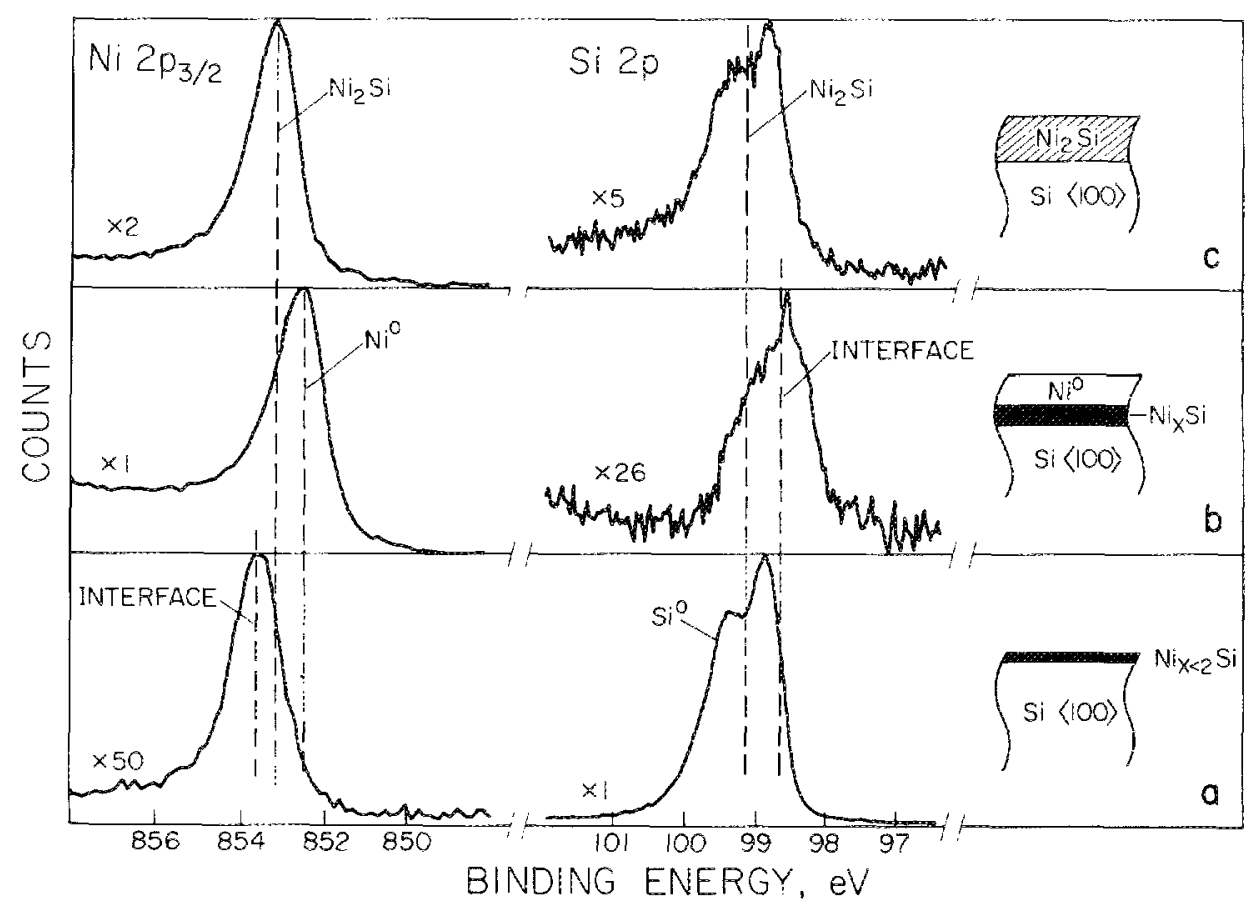

FIG. 7. Ni $2 p_{3 / 2}$ and corresponding $\$ i 2 p$ spectra obtained after (a) $\sim 0.2$ monolayers of $\mathrm{Ni}$ on $(100\rangle \mathrm{Si},(b) \sim 30$ monolayers of $\mathrm{Ni}$ on $\langle 100\rangle \mathrm{Si}$, and (c) final $250^{\circ} \mathrm{C}$ heat treatment. 
In Sec. III A.1, it was shown that the Ni $2 p$ binding energy of the $\mathrm{Ni}$ atoms present at the $\mathrm{Si} / \mathrm{Ni}_{2} \mathrm{Si}$ interface was shifted $0.7 \mathrm{eV}$ higher than the bulk $\mathrm{Ni}_{2}$ Si signal. In the thin $\mathrm{Ni}$ ilm deposition experiments discussed above, it was found that the initial Ni atoms present on the Si surface were chemically shifted only $0.4 \mathrm{eV}$ higher than bulk $\mathrm{Ni}_{2}$ Si. The additional 0.3 $\mathrm{eV}$ shift indicates that the $\mathrm{Ni}$ atoms in the transition region between $\mathrm{Si}$ and $\mathrm{Ni}_{2} \mathrm{Si}$ are in an even more Si-rich environment than the Ni atoms between Si and the vacuum. Clearly, the presence of the extended $\mathrm{Ni}_{2} \mathrm{Si}$ overlayer has affected the environment of the $\mathrm{Ni}$ atoms at the interface.

\section{CONCLUSIONS}

Two different approaches for the study of the $\mathrm{Ni} / \mathrm{Si}, \mathrm{Ni} /$ $\mathrm{Ni} \mathrm{Si}_{2}$, and $\mathrm{Si} / \mathrm{Ni}_{2} \mathrm{Si}$ interfaces have been used to study the chemical nature of these transition regions. The first approach examined the advancing planar interfacial region by $\mathrm{dy}$ namically monitoring the in situ formation of the silicide. The second approach followed the development of the $\mathrm{Ni} / \mathrm{Si}$ interface using UHV depositions of thin layers of $\mathrm{Ni}$ on (100) Si. Quantitative information on the atomic composition was obtained from $\mathrm{He}^{+}$backscattering.

These experiments have demonstrated that the $\mathrm{Ni} / \mathrm{Ni} \mathrm{Si}_{2}$ interface consists of a $\mathrm{Ni}$-rich silicide phase, while the $\mathrm{Si} / \mathrm{Ni} \mathrm{N}_{2} \mathrm{Si}$ interface shows a transitional region that is a correspondingly Si-rich silicide. Intensity analysis indicates that these transition regions are at least $22 \AA$ wide for amorphous-Si substrates and 9-14 $\AA$ for monocrystalline Si substrates. The as-deposited $\mathrm{Ni} / \mathrm{Si}$ interface cannot be described as a mique single-phase, but rather as a chemically graded transition region ranging in stoichiometry from $\mathrm{Si}$-rich to $\mathrm{Ni}$-rich silicides. It was also demonstrated that the $\mathrm{Ni}$ atoms at the $\mathrm{Si} / \mathrm{Ni}_{2}$ Si interface are in a more Si-rich environment than the $\mathrm{Ni}$ atoms at the $\mathrm{Si}$ / vacuum interface. This result suggests that care must be exercised in drawing conclusions concerning the stoichiometry and bonding at "realistic" interfaces using data obtained from sequential depositions or "less realistic" interfaces.

\section{ACKNOWLEDGMENS}

The authors wish to thank A. Madhukar for stimulating discussions. This paper presents the results of one phase of research performed at The Jet Propulsion Laboratory, California Institute of Technology, sponsored by the National Aeronautics and Space Administration under contract NAS7-100 and the Office of Naval Research (L. R. Cooper).

a)Present address: Department of Material Science, Cornell University, Ithaca, N.Y. 14853

FFor a comprehensive review of silicide studies, see review article by $\mathrm{K} . \mathbb{N}$. Tu and J. W. Mayer in Thin Films-Interdiffusion and Reactions, edited by J. M. Poate, K. N. Tu, and J. W. Mayer (Wiley, New York, 1978), p. 359.

2J. K. Freeouf, G. W. Ruboff, P. S. Ho, and T. S. Kuan, Phys. Rev. Lett. 43, $1836(1979)$.

3J. N. Miller, S. A. Swartz, I. Lindau, W. E. Spicer, B. DeMichelis, I. Abbati, and L. Braicovich, J. Vac. Sci. Technol. 17,920 (1980).

${ }_{4}^{4}$ ]. A. Roth (Thesis, University of Southern California, 1979).

${ }^{5}$ F. J. Grunthaner, J. Maseriian, IEEE Trans. Nucl. Sci. N5-24, 2108 (1977).

${ }^{6}$ W. K. Chu, J. W. Mayer and M-A. Nicolet, Backscattering Spectrometry, (Academic, New York, 1978).

${ }^{7}$ K. N. Tu, W. K. Chu, and J. W. Mayer, Thin Solid Films 25, 408 (1975).

${ }^{8}$ F. J. Grunthaner, P. J. Grunihaner, R. P. Vasquez, B. F. Lewis, J. Maserjian, and A. Madheikar, J. Vac. Sci. Technol. 16, 1443(1979).

${ }^{9}$ T. A. Carlson and G. E. McGuire, J. Electron Spectrosc. Relat. Phenom. $1,161(1972 / 73)$.

10J. M. Hill, D. G. Hoyce, C. S. Fadley, L. F. Wagner, and F. J. Grunthaner, Chem. Phys. Lett. 44, 225 (1976).

11P. J. Grunthaner and J. W. Mayer (io be published).

12]. L.'Ecuyer, J. A Davies and N. Matstinami, Nucl. Instrum. Methods 160, $337(1979)$.

${ }^{13}$ D. M. Scott, P. J. Grunthaner, and B. Y. Tsaur, presented at 156 th meeting of Electrochem. Soc., I. A., 1979 (to be published).

${ }^{14}$ D. R. Penn, J. Electron Spectrose. Relat. Phenom. 9, 29 (1976) 